\title{
Use of Interactive Graphic Organisers for Developing Cognitive Skills in Higher Education
}

\author{
Mario J. Lopez, Hector R. Ponce, Rodrigo G. Quezada \\ VirtuaLab-USACH, Departamento de Ingeniería Industrial, \\ Universidad de Santiago de Chile, Chile
}

\begin{abstract}
This article presents research findings from a curricular integration experience of a software application denominated Interactive Graphic Organiser. Such integration was implemented through a series of learning activities in the Information Systems Design course that belongs to the seventh semester in the Industrial Civil Engineering degree at the University of Santiago of Chile. A set of eight different types of graphic organisers were used to foster the development of a series of cognitive skills and appropriation of specific disciplinary content. Research was conducted through a cuasiexperimental design where students from the experimental group (the course) were invited to use the selected set of graphic organisers in their learning and assessment activities. A working hypothesis was tested for the curriculum integration, confirming that the use of graphic organisers significantly improved the involved cognitive skills and the assessed disciplinary content.
\end{abstract}

\section{Introduction}

Interactive Graphic Organisers (IGOs) are software that combine non-linguist representations (shapes, symbols and arrows) with linguist elements (words and phrases). Interactive Graphic Organisers facilitate the discovery and design of patterns, relationships, and interrelationships, as well as helping to develop creative thinking.

This article presents a case study in which a set of IGOs associated with a group of thinking skills were integrated into a course curriculum in higher education. The paper begins with a description of the research problem. It then presents some background information: a conceptual summary; a IGOs description, including those used in the experiment; the used approach to ICT curricular integration; and some details about the course. Next, it presents the evaluation design. The main findings are presented in terms of quantitative impacts and students perceptions. Finally, a couple of conclusions are outlined.

\section{Research focus}

The research was conducted into an information systems design course, which belongs to the seventh level (out of twelve) of the Civil Industrial Engineering degree at the University of Santiago, Chile. The course runs for 17 weeks with 102 hours per semester. Week activities include 1 hour lecture; 2 hours seminar, 2 hours laboratory assignment. Other semester intermittent activities were 12 hours case discussion and time for assessing.

According to the course lecturers, after several semesters running and assessing students on the course, they had noticed that the students evidenced an inadequate thinking skills level important for course content understanding. Students usually confuse problem origins and consequences; incorrectly identify attributes to compare objects; have difficulties structuring sequences and so on.

For example, as the course starts, students must state a real organizational problem, in which information management is an important component. The problem wording was of great complexity in previous semesters, students showed weaknesses in their ability to distinguish between problem symptoms (causes) and problem consequences (effects); often the problem was associated with some of its symptoms.

Another example is their difficulty to complete a promise structured syntactic (actor $1+$ fixed verb + action + actor 2)

Given the diagnosis, and as Interactive Graphic Organisers software was designed to practice and develop thinking skills, it was decided to integrate the IGO software into learning activities to improve students evidence production through developing thinking skills critical to the subject understanding.

The IGOs' use sought to develop on the students a deep learning approach through making available to them these technological artefacts. 


\section{Background}

Because the IGO software curricular integration looked for students memorable experiences, background elements presented are experiential learning, deep learning, visual learning, interactive graphic organisers and ICT curricular integration model. The background ends with some of the course details.

\subsection{Experiential learning}

The crucial question that this approach addresses is how students learn. Although originally formulated to address the question of adult education, it has made an important contribution to understand how students learn in general. In this approach, learning is a process in which "people generate from their experience the concepts, rules and principles that guide their behaviour in new situation" [15]. The effectiveness of their behaviour depends on how they adapt their concepts, change their rules or discover new guiding principles.

Learning takes place through a continuous and recurrent sequence of actual experiences and, as experiences by themselves are insufficient, they are accompanied by thought, observation, and abstract concept construction and trying out these concepts in new experiences. Thus, the learning process has a four-stage cycle. (1) Concrete experiences are followed by (2) observation and reflection of such experience, which leads to the (3) formation of abstract concepts and the constructions of principles or generalisations, followed by (4) the testing of such concepts in new situations.

\subsection{Deep learning}

Deep learning is within the constructivist view and it is regarded as the opposite to memory based or repetitive learning [3]. Deep learning arises when substantive and non-arbitrary relationships are built between what it is already known (previous content) and what it is to be learnt (new content) [7]. Thus, learning is an active process where new understandings are built by designing and creating meaningful experiences for learners. This should facilitate the organization of learner's cognitive structure $[9,13]$.

Three requisites are required to accomplish deep learning. Firstly, content logical significance. This means that content structure should facilitate how learners build relations between new and their previous knowledge. Secondly, psychological significance of content, related to the internal representation made by learners of logical significant of content. Thirdly, learners' favourable attitude given by the disposition to substantively, profoundly and no literally relate their cognitive structure with the new material [14]. The presence of deep learning in educational environments depends upon the mediation between didactic (methods and strategies) and learning outcomes. This requires a rigorous and systematic teaching and learning planning, including content and aims characteristics, learner starting level, methods, didactic sequences, and learning strategies to facilitate deep meaning of contents and activities.

Basic cognitive operations such as observation, comparison, classification, analysis and synthesis are better developed when learning activities consciously put emphasis on their need to process content and create new knowledge [1].

\subsection{Visual learning}

An important set of learning strategies requires mental representations that result in visual schemes for their understanding. For example, there are learning techniques as simple as paragraph underlining and margin notes, and other techniques that require complex cognitive processes, such as conceptual mapping.

The advantages of introducing strategies that require visual representation are diverse and based on the fact that about $80 \%$ of perceived information comes through the visual channel. A visual learning principle is that students, using visual tools, can clarify their thinking, enhance their understanding, integrate new knowledge and, additionally, identify misconceptions [11]. A visual scheme allows students to discover and design patterns, interrelationships and interdependencies, and provide opportunities to develop creative thinking. For example, through a differences and similarities diagram, students have a visual strategy that allows them to identify similarities and differences between two or more objects. This technique facilitates reading skills, develops diagramming abilities, and synthesis through structured analysis registration of similarities and differences. Graphic organisers are typical representatives of visual learning. Graphic organisers encourage the development of structured activities; help to display content in a graphical form, and support the development of cognitive skills [18].

\subsection{ITC curricular integration}

ICT effective use in education is widely reported and interesting examples are $[4,16,17]$. The literature, however, is not as abundant on ICT curricular integration models; for example, there are proposals for languages [19], science and social science [2]. All place great emphasis on the teacher willingness 
[10] and are based on means and content provision [6].

We work with an ICT curricular integration model based on learning to learn, skills and values development, and teachers as facilitators of students learning [20].

This model proposes learning outcomes specification through skills and abilities (cognitive domain); values and attitudes (affective domain); significant contents (knowledge architecture) and methods or learning activities. These elements are arranged in a double $\mathrm{T}$ [20], as shown in Figure 1. The model includes contents and methods assessment.

\begin{tabular}{|c|c|c|}
\hline Contents & Means & Methods/activities \\
\hline Skills/abilities & Objectives & Values/attitudes \\
\hline
\end{tabular}

Figure 1. Double T.

The $\mathrm{T}$ model facilitates curricular integration of ICT as means for learning activities, which ensures that the use of ICT is strategic [5], particularly to facilitate evidence gathering and assessment by portfolio.

\subsection{The course}

The course was in the Industrial Civil Engineering degree course. The Information System Design course is in the fourth year of study out of a six and it has three content units (information system analysis, design and prototype production). The course organised content and learning activities following Kolb's four stages model.

There was one lecture per unit for students to construct abstract concepts. To provide students with new learning experiences, teams of three students develop a project throughout the course; the project goal was to solve a real world information problem, which had to be carried out in a private or public company as a case study. To give students opportunities of thought and observation, seminars were organised with the teams. The seminar's aim was to assess and give feedback on the progress of each project. Students' observations and reflections were assessed through interim and final reports on the case study.
Additional support was structured through responses to students' e-mails, which were given within 24 hours. 'Chats' between the teaching team and students and among students were frequently conducted.

Course assessment was based upon portfolio building and included paper reading, essays, assignments, reports, dissertations, and written tests. About half of these were carried individually and the other half in groups. Assessment took place as course work, workshops and each unit ended with an individual examination.

\subsection{Interactive Graphic Organizes}

Most of the learning activities were based upon the use of Interactive Graphic Organisers, particularly those that aimed at developing thinking skills. The use of visual aids and diagrams, such as graphic organisers, facilitate structured thinking, reinforces understanding, facilitate the integration of new knowledge and allow identification of conceptual errors [12]. These visual artefacts also facilitate patterns the discovery of interrelationships and interdependencies, as well as the development of creative thinking. For example, through a similarities and differences diagram, a student has a visual technique that enables him/her to compare two or more objects or events.

The software Interactive Graphic Organisers are visual diagrams developed using software components technology [8] and implemented in Adobe Flash. This allows easy integration into Web environments and Flash compatible software.

As shown in Figure 2, each organiser has functionalities in a tool bar to create, edit, remove, store, retrieve and print what a student is developing or has completed interactivity through adding and editing graphic forms.

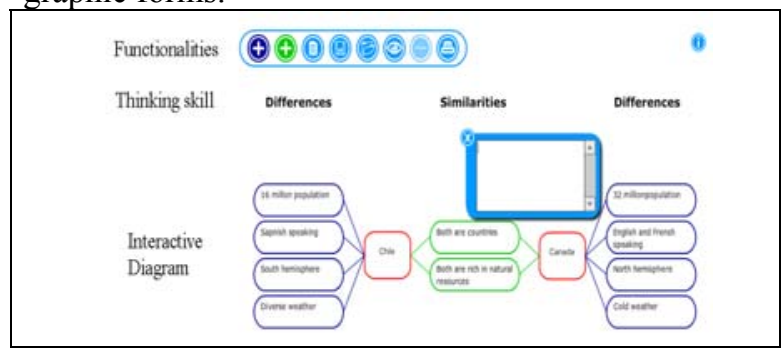

Figure 2. IGO structure.

The Interactive Graphic Organisers' features grant them a high degree of interactivity, facilitating in particular (1) cognitive skills development and (2) reading comprehension:

Cognitive skills development: IGOs are particularly useful for challenges where students are required to develop an idea or order thoughts. Here 
IGOs become well-defined structures that guide students thinking; students enter in a systematic dialogue with themselves (meta cognition and meta learning) assisted with a technological tool.

Reading comprehension: IGOs provide direct support to reading understanding by allowing the reader-learner to make sense and extract meaning before, during and after reading.

Interactive Graphic Organisers are grouped into six categories, one is cognitive abilities and includes the following diagrams: Analogy, Brainstorming, Cause and Effect, Comparison, Definition, Differences and Similarities, Sequencer, Dual Descriptor, Fishbone, Hierarchic Semantic Map, Hierarchy, Orbital, Pro Con, Puzzle, Pyramid, Semantic Map, Snapshot, Spider, Synonym and Antonym, System, and Timeline.

Another category is Matrixes and Templates, which includes the diagrams 5Ws, Before and After, Comparative Matrix, Feelings and Colours, Five Senses, Food Analysis, Generic Matrix, Generic T, Learning Means T, Learning Outcomes T. Multicriteria, My Learning KWL, My Routine, Scheduling, Synonym and Antonym Matrix, and Time Matrix.

The research reported here used a few of these organisers.

\section{Research design}

One of the major problems addressed by the research was the structuring of a promise workflow, which was essential for the information system analysis. Here, students had difficulties to complete a predefined promise syntactic structure. The IGO used for this case was the generic matrix, adapted as Promise Matrix, with predefined syntactic as headings.

Another difficulty was the students' phrasing of an information based company problem. Students tended to confuse problems with its causes or consequences. The IGO used for this case was the Cause and Effects Diagram, which has related text boxes to indicate causes, problem and effects.

A third difficulty was with business rules specification. Students had problems with rules classification and prioritisation. The IGO used for this case was the Box Linker, which allows rules identification and classification.

A fourth problem was related to the identification of elements to be programmed. Students had difficulties with the selection of what to programme. The IGO used for this case was the Brain Storming, which allows a limited number of ideas to be written.

The fifth problem was connected to their information system prototype's logical components design. Students had difficulties with components right order. The IGOs used for this case were Brainstorming and Sequencer, which has a predefined sequence to enter events.

The underlying research hypothesis was that use of IGOs would have a positive effect on students.

A cuasi-experimental design was used with control and experimental group. Students on the course during 2008's first university term constituted the experimental group. Students on the same course but taken on 2007's second university term constituted the control group. Therefore, different students constituted the control and experimental groups.

The experimental group (the course) participated in learning activities that integrated the IGO software. Students in the experimental group were asked to use seven IGOs in ten different learning activities. IGOs implemented were: Cause and effect (problem, origins and consequences discrimination); Generic Grid (events analyses under variables); Definition (concept construction); Box Linker (relations between initial and other elements); Comparison (nonrandomly objects comparison); Brainstorming (ideas representation); and Sequence (dependency relationships).

Typically, learning activities included learning outcome identification; activity's name and brief description; IGO(s) to be used (if appropriate), and step-by-step instructions for producing digital and physical evidence. Figure 3 illustrates a learning activity (challenge) that integrates the "Cause and Effect" IGO software.

Challenge 1: Identify and summarize a real information problem.

Description: You will need to state an information problem, differentiating it from its causes and effects.

File: CauseEffect.swf

Hint: Use software tool tips o find IGO functionalities. For any doubts, please ask your assistant.

\section{Instructions}

1. Download, open and save a Word document with the name "InformationProblem.doc". Enter your name, course and company name.

2. Briefly describe the company and its information problem.

3. From your description, list problem's relevant issues.

4. Download and open CauseEffect.swf. Enter your problem in the red box. Use the blue + button to insert cause boxes, enter causes in the blue boxes. Use the green + button to insert effect boxes, enter effects in the green boxes. Save the file with "InformationProblem.ceigo" as its name.

5. Once done, please save all files and upload them to your working folder.

\section{Figure 3. Learning activity.}

Learning activities were assessed through previously generated checklists. Figure 4 shows the 
checklist for the above learning challenge (Figure 3).

\begin{tabular}{|c|c|c|c|c|}
\hline Indicator & \multicolumn{2}{|c|}{ Description } & $\underset{\%}{\operatorname{Max}}$ & $\%$ \\
\hline \multirow{2}{*}{ Evidences } & \multicolumn{2}{|c|}{$\begin{array}{l}\text { InformationProblem.doc } \\
\text { (description and issues list) }\end{array}$} & 10 & \\
\hline & \multicolumn{2}{|c|}{$\begin{array}{l}\text { InformationProblem.ceigo } \\
\text { (causes-problem-effects) }\end{array}$} & 5 & \\
\hline \multirow{3}{*}{ Pertinence } & \multirow{3}{*}{$\begin{array}{l}\text { Correctly } \\
\text { define }\end{array}$} & Problem & 10 & \\
\hline & & Causes & 10 & \\
\hline & & Effects & 10 & \\
\hline Consistency & \multicolumn{2}{|c|}{ Between .doc and .ceigo. } & 10 & \\
\hline Synthesis & \multicolumn{2}{|c|}{ Analysis and conclusion. } & 45 & \\
\hline \multicolumn{3}{|c|}{ Results } & 100 & $\Sigma$ \\
\hline
\end{tabular}

Figure 4. Checklist.

To evaluate the impact of the curricular integration of the IGO software on students learning and study practices quantitative data gathered from the experimental and control groups was analysed as well as analysis made from data gathered through interviews, focus groups, and student activities observation.

\section{Findings}

Findings regarding the use of IGOs by the engineering students are presented both quantitatively and qualitatively.

\subsection{Quantitative analysis}

The effects of two IGOs on students' learning are presented; the first one relates to the use of the Generic Matrix to develop a group activity, and the second, it is the use of the Cause-Effect Diagram on individual activities.

5.1.1. Generic matrix. To compare the results on group learning, the groups' reports by the 2008 first university term (experimental group) were compared with the groups' reports by students on 2007 second term (control group). The control group was formed by a different group of students and they did not use any of the graphic organisers.

Both, experimental and control groups, were given the same task: to structure a promise workflow. To work on the task, the students form small work groups of 3 or 4 members. The control group was formed by 9 workgroups and the experimental group by 14 workgroups.

The difference between the control and experimental group is that to structure the promise workflow, the experimental group was asked to additionally use and complete a Generic Matrix, indicating actors, verbs and actions (elements of the promise workflow). The control group, on the other hand, directly structured the promise workflow. Figure 5 presents the structure of the generic matrix adapted for the workflow:

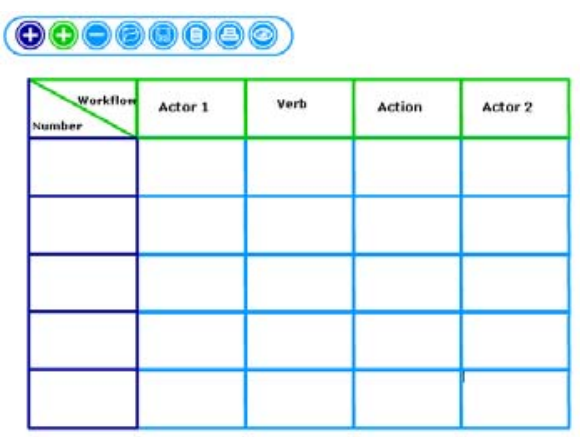

Figure 5. Generic Matrix IGO.

The quality of the promise workflows by the control and experimental groups were assessed by a two experts using a 1 to 7 scale (assessing scale used in Chile).

Table 1. Mean and Stdv of promise workflow task.

\begin{tabular}{|l|l|l|}
\hline \multicolumn{1}{|c|}{ Groups } & Mean & Stdv \\
\hline Control & 5.633 & .9500 \\
\hline Experimental & 6.571 & .3667 \\
\hline
\end{tabular}

The results from the assessment were normally distributed and a t-test was used to compare the means. The experimental group shows a significant improvement compared with the control (t-student $=$ $2.83, \mathrm{p}$-value $=.01, \mathrm{df}=9$ and $\alpha=.05$ ).

Thus, the use of the generic matrix IGO had a positive impact on the task related to structuring a promise workflow.

5.1.2. Cause and effect diagram. The same groups - control and experimental - were assessed regarding now their individual skills to formulate and frame a problem situation. The experimental group, formed by 45 students, used the IGO called "Cause and Effect Diagram" to facilitate the task. The control group, formed by 35 students, did not use any IGO.

Two experts assessed the quality of the problem formulation and frame.

Figure 6 shows the structure of the cause and effect Interactive Graphics organiser. 


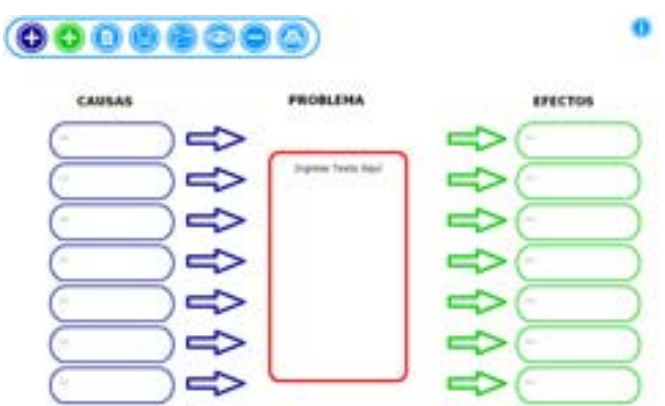

Figure 6. Cause and effect IGO.

Table 2. Mean and Stdv of problem formulation task.

\begin{tabular}{|l|c|c|}
\hline \multicolumn{1}{|c|}{ Groups } & Mean & Stdv \\
\hline Control & 5.523 & 1.292 \\
\hline Experimental & 6.066 & 0.949 \\
\hline
\end{tabular}

The analysis indicates that the experimental group shows a significant improvement compared with the control (t-student $=2.16, \mathrm{p}$-value $=.034, \mathrm{df}$ $=78$ and $\alpha=.05)$.

Thus, the use of the cause and effect IGO had a positive impact on the task related to formulating and framing a problem situation at individual level.

In both cases, the use of IGOs by students on their group tasks and on their individual tasks shows significant improvements compared to those students that did not use this technological artefact.

5.1.3. Box Linker diagram. To compare group learning outcomes on determination of business rules, group reports from the experimental group (first term 2008) were compared with reports from the control group (second term 2007).

Both groups, experimental and control, were given the same task: to determine restrictive and derivate business rules. To carry out the task, students formed groups of three or four members. Students in the experimental group formed 14 workgroups and students in the control group constituted 9 groups. The only difference between experimental and control groups was that the experimental group used and completed twice the Box Linker IGO. This IGO was used twice, the first time, to indicate the restrictive business rules, and the second time, to structure the derivate business rules. The Box Linker IGO required students to write in circle of the diagram the identified business rule and to identify up to six associated rules, using the soft-square available in the IGO. On the other hand, the control group addressed the business rules assignment without IGO assistance. Figure 7 shows the interactive structure of Box Linker IGO.

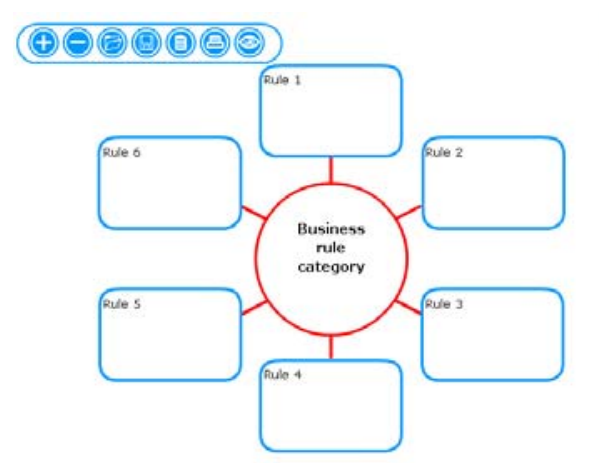

Figure 7. Box Linker IGO

Two of the teaching assistants in the course assessed the business rules' quality.

Table 3. Mean and Stdv of business rules task

\begin{tabular}{|l|c|c|}
\hline \multicolumn{1}{|c|}{ Groups } & Mean & Stdv \\
\hline Control & 5,433 & 1,655 \\
\hline Experimental & 6,443 & 0,797 \\
\hline
\end{tabular}

As the data proved not to be normally distributed, a non-parametric test was computed. The analysis indicates that the experimental group showed a significant improvement compared with the control group (Mann-Whitney $\mathrm{U}=36.5$, $\mathrm{p}$-value $=.046$, and $\alpha=.05)$.

Therefore, the use of the Box Linker IGO had a positive impact on the task associated with the identification and classification of business rules at the groups' level.

\subsubsection{Brain Storming and Sequencer diagrams.}

The same experimental and control groups were assessed for their ability to design logical components of their computer application prototype. The experimental group was made up by 14 teams and the control group by 9 teams. Both groups were asked to design the logical components of their information system prototype. The experimental group made use of two Interactive Graphic Organisers for the assignment, while the control group did not use any graphic organisers.

The control group design ended to be both very intuitive and software applications disorderly listed. The experimental group had support from two Interactive Graphic Organisers. Initially from the Brainstorming IGO, this enabled them to list all necessary components that their prototype should have included. The complete list was then analysed, prioritized, and entered into the Sequencer IGO. Figure 8 shows the structure of the Interactive Graphic Organisers Brainstorming and Sequencer. 

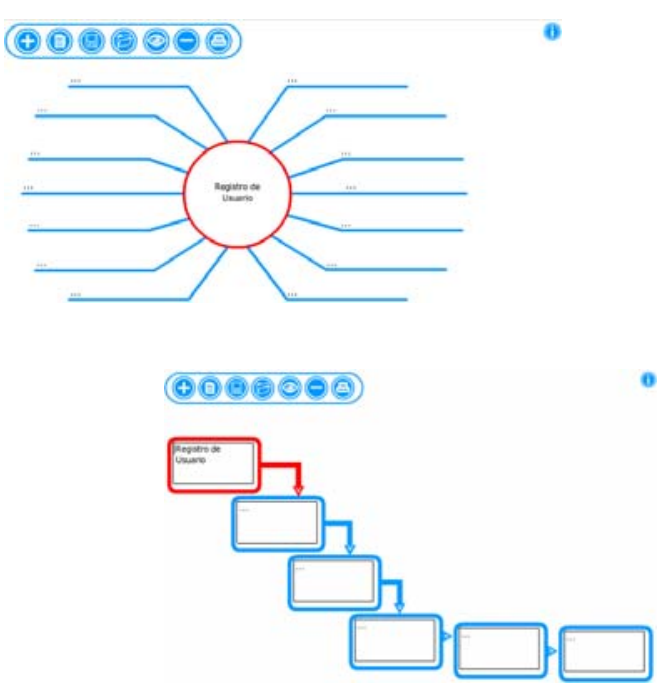

Figure 8. Brainstorming and Sequencer IGOs.

Two of the teaching assistants in the course assessed the prototype logical structures quality.

Table 4. Mean and Stdv for pseudo programmes.

\begin{tabular}{|l|c|c|}
\hline \multicolumn{1}{|c|}{ Groups } & Mean & Stdv \\
\hline Control & 5,456 & 0,354 \\
\hline Experimental & 5,757 & 0,739 \\
\hline
\end{tabular}

The data was not normally distributed, so a nonparametric test was computed. The analysis shows that the experimental group had a significant improvement compared with the control group (MannWhitney $\mathrm{U}=34.5$, $\mathrm{p}$-value $=.037$, and $\alpha=.05$ ).

Therefore, the use of Brainstorming and Sequencer IGOs had a positive impact over the assignment results on producing a programme pseudo coding.

5.1.5. Prototype production. Each of the course content ended with a three hours individual written examination workshop. For the third unit, given a partial information system design, students had to programme the corresponding prototype. The experimental group, made up of 55 students had IGOs available as support, while the control group, 35 students, did not have any IGO available.

Two of the teaching assistants in the course as well as one of the lecturers marked the third written examination.

Table 5. Mean and Stdv third written examination.

\begin{tabular}{|l|c|c|}
\hline Groups & Mean & Stdv \\
\hline Control & 3,231 & 0,569 \\
\hline Experimental & 3,714 & 1,194 \\
\hline
\end{tabular}

The analysis show that the experimental group had a significant improvement compared with the control group (t-student $=2.57, \mathrm{p}$-value $=.01, \mathrm{df}=$ 83 and $\alpha=.05)$.

Therefore, the use of IGOs had a positive impact on individuals to develop an information system prototype from a partial design.

\subsection{Students perceptions}

Information from students showed that IGOs curricular integration most valued aspects were: (1) structural thinking, (2) keep focus on what matters, (3) advantages of using IGOs, and (4) usability strengths of using IGO. Students also had some critical observations, such as course structure and some aspects of usability.

5.2.1. Structural thinking. Students thought that IGOs use helped them not only to think but also to think more structurally, think with more sense, organise ideas more easily and synthesise more rapidly. Some students' remarks were:

"I found that the tool was useful to organize ideas and to enable the identification of what are causes and what are effects... One is conditioned to think in that way when faced with a problem and have the experience to deal with. I will know that the obtained optimal response is modelled following the pattern of the graphic organiser, which allows avoiding confusion, leaving a record of thoughts and one becomes aware that everything can be so orderly."

"One realizes that in reality this is spinning, and as I said to my fellow students, it helps us organize and focus the ideas, because sometimes you have an idea in your head, but a thousand things come to mind, while here synthesis is easier and so useful"

"The way we work in this course is great, it's so easy to deviate and you say $¡$ ah! I want this but the company wants that, but I am solving a problem and have to be more specific. This is something incredible, one is forced to synthesize."

5.2.2. Focus on the relevant. Students considered that using the IGO software allowed then keeping focus on what mattered to the course: solve an information problem through an information system design and prototype. A couple of quotes from students are:

""IGOs serve to emphasize the central fact, and do not misunderstand the sense of making new things, very useful for the course purposes. The clear problem definition made me aware that I had to design a solution." 
"What is sought is to solve an information problem and avoid being impressed by complex programming and in that IGOs were absolutely useful."

5.2.3. Course strengthening. Students said that IGOs use strengthened the course, because the use of innovative tools. Students, for example, said:

"I learnt to use a tool which helps me to solve problems. There is a perception change from programming to design. It is useful and with a lot of potential for future use".

"I appreciated the weekly deliveries; it keeps a good study pace and the use of IGO tools helped not only to understand and learn course content, but also to finish the assignments on time"

5.2.4. IGOs advantages. IGOs use presented various advantages for students, among them:

"They accomplish its function for visually present and understand course content. Information within the IGO allowed an easy ride on course contents through easy organization of ideas, concepts and information".

"IGOs allowed permanent contact with the initial problem. May be, without the Interactive Graphic Organisers, the solution would have not been possible and we had ended with a set of pretty windows only. The second time I used the Cause and Effect IGO, I realised how the course unit are related and it was so much easier to learn".

5.2.5. IGOs usability. Students recognised that IGOs are easy to use; at first sight, colours are attractive; and they are visually simple. Students reckoned that IGOs simplicity is their most outstanding feature, in contrast to traditional educational software, which have infinity options and buttons, many never used.

5.2.6. Disadvantages. Students mentioned two aspects that can be categorised as disadvantages. First, they found difficult to get used to the course style with weekly assignments and practically giving a couple of hours daily. "At the beginning it is difficult, it is hard to assume continuous work, until you get used to it", as one student put it.

Other critical points were the small amount of text that IGOs allowed and the complexity to save them. Both amendments were quickly introduced to IGOs.

\section{Conclusions}

The quantitative and qualitative evidence proved the research hypothesis, which stated that the use of IGOs would have a positive effect on students.
Quantitative data showed that:

- The group use of the Generic Matrix IGO had a significant impact for structuring a promise workflow.

- The individual use of the Cause and Effect IGO had a significant impact for formulating and framing a real problem.

- The group use of the Box Linker IGO had a significant impact for the identification and classification of business rules.

- The group use of the Brainstorming and Sequencer IGOs had a significant impact for producing a programme pseudo coding.

Qualitative data showed that IGOs are easy to use and allowed students:

- To think more structurally.

- To keep focus on what mattered.

\section{References}

[1] Amestoy, M. (2002). La investigación sobre el desarrollo y la enseñanza de las habilidades de pensamiento. Revista Electrónica de Investigación Educativa. Vol. 4 (1), 129-159.

[2] Ashburn, E. \& Floden, R. (2006) (Editors). Meaningful Learning Using Technology: What Educators Need to Know And Do. New York: Teacher College Press.

[3] Ausubel, D. (1963) The Psychology of Meaningful Verbal Learning. Nueva York: Grune and Stratton.

[4] Becker, H.J. (1994). Mindless or mindful use of integrated learning systems. International Journal of Educational Research, 21, 65-79.

[5] Burge, E. (2001). The Strategic Use of Learning Technologies: New Directions for Adult and Continuing Education. Jossey-Bass.

[6] Chen, I. \& ThielemannHershey, J. (2007). Technology Application Competencies for K-12 Teachers. Hershey, PA: Information Science Publishing.

[7] Coll, C. (1991).Aprendizaje escolar and construcción del conocimiento. Barcelona: Paidos.

[8] D'Souza, D., \& Wills, A. (1998). Objects, Components and Frameworks: The Catalysis Approach, Reading, MA: Addison-Wesley.

[9] Entwistle, N. (1981) Styles of Learning and Teaching: An Integrated Outline of Educational Psychology for Student, Teachers, and Lecturers. Chichester: John Wiley \& Sons

[10] Gallego, M. (2001). El profesorado y la integración curricular de las nuevas tecnologías. En Area, M. (Coord.). Educar en la sociedad de la información. Bilbao: Desclée De Brouwer. (pp. 383407). 
[11] Gardner, H. (2003). Inteligencias Múltiples: la teoría en la práctica. Buenos Aires: Paidos.

[12] Gardner, H. (2003). Inteligencias múltiples: la teoría en la práctica. Buenos Aires: Paidos.

[13] Gibbs, G. (1999) Teaching in Higher Education: theory and practice, how students differ as learners, Milton Keynes: Open University

[14] Gibbs, G., Morgan, A., and Northedge, A. (1998) Teaching in Higher Education: theory and evidence, how students learn, Milton Keynes: The Open University.

[15] Kolb, D., Rubin, I. and Osland, J. (1991). Organizational Behaviour: an experiential approach. New Jersey, Prentice-Hall

[16] Kulik, J.A. \& Kulik, C-L.C. (1987). Review of recent literature on computer-based instruction. Contemporary Education Review, 12, 222-230.

[17] Liao, Y.K. (1992). Effects of computer-assisted instruction on cognitive outcomes: A metaanalysis. Journal of Research on Computing and Education, 24, 367-380.

[18] Marzano, R., Pickering, D. \& Pollock, J. (2001). Classroom Instruction that Works: Research Based Strategies for Increasing Student Achievement. Virginia: Association for Supervision and Curriculum Development

[19] Quesada, A. (2003). Nuevas tecnologias de la información y la comunicación: integración en el aula de idiomas. Revista de Filología y Lingüística de la Universidad de Costa Rica. Volume: 29 Issue: 2 Page: 193(7)

[20] Román, M. (2005). Sociedad del Conocimiento y Refundación de la Escuela desde el Aula. Barcelona: Ventrosa Impresores. 